\title{
Design of hybrid clay/ polypyrrole decorated with silver and zinc oxide nanoparticles for anticorrosive and antibacterial applications
}

\author{
Khouloud Jlassi $^{\mathrm{a}, *}$, Mostafa H. Sliem ${ }^{\mathrm{a}}$, Fatiha M. Benslimane ${ }^{\mathrm{b}}$, Nahla O. Eltai ${ }^{\mathrm{b}}$, \\ Aboubakr M. Abdullah ${ }^{\mathrm{a}, *}$ \\ ${ }^{\text {a } C e n t e r ~ f o r ~ A d v a n c e d ~ M a t e r i a l s, ~ Q a t a r ~ U n i v e r s i t y, ~ D o h a ~ 2713, ~ Q a t a r ~}$ \\ ${ }^{\mathrm{b}}$ Biomedical Research Center, Qatar University, Doha 2713, Qatar
}

\section{A R T I C L E I N F O}

\section{Keywords:}

Clay

Polypyrrole

Zinc oxide

Hybrid materials

Corrosion resistance

Antibacterial

Cytotoxicity

\begin{abstract}
A B S T R A C T
In this work, a novel and cost-effective bentonite intercalated with polypyrrole Zinc oxide-silver nanocomposite (B-PPy/ZnO) hybrid material was prepared via in situ photopolymerization of pyrrole in the presence of silanized bentonite and zinc oxide nanoparticles and using silver nitrate as an initiator. The as-prepared Bentonite-polypyrrole/ZnO hybrid material was found to be black, exfoliated with a polypyrrole-rich surface decorated with $\mathrm{ZnO}$ and silver nanoparticles in a metallic state. We evaluated the propensity of the prepared hybrid material as an eco-friendly, anticorrosive, and antibacterial coating for carbon steel. The corrosion resistance efficiency study of B-PPy/ZnO composite incorporated with the epoxy matrix was carried out in a $3.5 \% \mathrm{NaCl}$ solution. B$\mathrm{PPy} / \mathrm{ZnO} 4 \mathrm{wt} \%$ composite coating on carbon steel was observed to exhibit best corrosion protection property, with High charge transfer resistance were value $\left(9.85 \mathrm{M} \Omega \mathrm{cm}^{-2}\right)$ compared to $0.213 \mathrm{M} \Omega \mathrm{cm}^{-2}$ in the presence of pure epoxy. Cytotoxicity assay was carried out on an A549 epithelial cell line. Moreover, B-PPy/ZnO showed a reduction in Escherichia coli bacterial growth by $\sim 86 \%$ with a minimum inhibitory concentration of $0.03 \mathrm{mg} \mathrm{ml}^{-}$ 1 . The results obtained herein will open new routes to the preparation of efficient ecofriendly anticorrosion and antibacterial coatings.
\end{abstract}

\section{Introduction}

Nowadays, researchers have devoted more interest in designing low cost, and multifunctional bio-based hybrid nanocomposite materials, for emerging and simultaneous applications such as; drug delivery Water treatment, flexible energy devices [1], energy conversion [2], solar cells devices [3], lithium batteries [4], actuators [5], antibacterial [6] and anticorrosive coatings [7]. Especially metal corrosion is considered, as one of the most severe problems in industries, it may cause enormous damages mainly to pipelines or storage tanks [8], and it may pose a severe threat to the environment [9]. Many strategies were developed in order to protect metallic surfaces against corrosion. However, the corrosion phenomenon was not entirely prevented but only controlled via cathodic protection, corrosion inhibitors, or, most commonly, the usage of protective coatings [10]. Clay- conductive polymers are a relatively new class of composite materials that have been recently used as an anti-corrosive protective coating $[11,12]$, because of their unique chemical and physical properties. The most popular conductive polymers are; polythiophene [13], polyaniline [14], and polypyrrole (PPy) [15], especially PPy is an ideal electroactive polymer to design smart coatings because of its easy preparation, biocompatibility and antioxidant properties [16-19]. Previous studies show that PPy could act as a physical barrier to prevent aggressive chemical reactions [20], as well as polymeric inhibitors leading to lower corrosion rate of iron [21].

Moreover, the redox behavior of PPy was found to provide selfhealing properties to scratched coatings [16]. However, its chemical sensitivity and poor mechanical properties limited its industrial uses. Nevertheless, many previous studies confirmed that the incorporation of PPy with other polymers, nanoparticles, or biobased materials such as cellulose or clay minerals [22] was found to improve the PPy stability and sensitivity [23,24]. Previous studies, in our team described the preparation of low-cost and conductive clay-PPy nanocomposites, with enhanced antibacterial, catalytic properties [24-26]. The latter has been prepared through different methods, such as chemical, electrochemical and photochemical polymerization [27], and it was found that clay

\footnotetext{
* Corresponding authors.

E-mail addresses: khouloud.jlassi@qu.edu.qa (K. Jlassi), abubakr_2@yahoo.com, bakr@qu.edu.qa (A.M. Abdullah).
} 
pretreatment using organic moieties, as coupling agents, will act as anchoring agents for the pyrrole monomer, leading PPy-rich clay surface with improved properties [28].

Moreover, Oxides nanoparticles such as zinc oxide ( $\mathrm{ZnO})$ were widely used as functional additives in anticorrosive coatings [29], because of their unique properties; including high surface area, nontoxicity, antibacterial $[30,31]$, corrosion resistance as it may act as adherent and thin protective film [32], acting as a barrier for moisture or oxygen transportation pathways in anticorrosive coatings [15,33]. The presence of nanoscale oxides was found to significantly improves the barrier properties and prolong the lifetime of the protective coatings; However, when exposed to aggressive industrial media, such as aggressive cleaning using acids, these may lead to zinc oxide loss. Herein we wished to investigate the propensity of clay/PPy as low-cost, bio-based micro-platforms for the immobilization of zinc oxide via photopolymerization. The as-prepared bio-based material was first analyzed using several techniques, such as $\mathrm{x}$-ray photoelectron spectroscopy (XPS), x-ray diffraction (XRD) and scanning electron microscopy (SEM), then mixed with epoxy resin and tested for challenging and smart applications, such us simultaneous ecofriendly, antibacterial in presence of Escherichia coli and anticorrosive coating anti-corrosion coating in $3.5 \mathrm{wt} \% \mathrm{NaCl}$ media.

In this work, we aim to investigate the propensity of bentonitemodified polypyrrole, to immobilize metallic nanoparticles, therefore, providing bio-based hybrid material and thus impart a tremendous benefit to the low-cost bio-based supports. Silver and zinc oxide NPs were selected, as their in-situ synthesis from adsorbed metal salt is facile and well known [34,35]. Furthermore, the immobilization of metal nanoparticles on reactive bentonite clay is an efficient strategy to provide well-dispersed nanostructures and thus take advantage of their high surface to volume ratio. One key aspect of this work is counterbalancing the high cost of metallic nanoparticles by employing low-cost supports. Hereafter, these composites will be used as simultaneous antibacterial and anticorrosive coatings.

\section{Experimental}

\subsection{Materials}

The used bentonite clay was extracted from the Gafsa-Tunisia; the longitude, Lambert coordinates is about 6 grads and $69 \mathrm{~min}$ (east) and the latitude of $38^{\circ}$ and $27 \mathrm{~min}$, north), after extraction the bentonite clay was purified following standard procedure in order to obtain, mono-sodic purified bentonite. Pyrrole (Aldrich), Silver nitrate and 3aminopropyl-triethoxysilane, were purchased from Sigma Aldrich and used as received. A kit of Epoxy resin 815 and its curing agent was purchased from BDH chemicals. Carbon steel plates, used as substrates for the prepared coatings, were purchased from Hebei Yineng Pipeline Group Co, Ltd, China, were polished using silicon carbide ( $\mathrm{SiC}$ ) papers ranging from 200 to 1000 grit size, then cleaned many times using deionized water and acetone before coating. The organic solvents used were of analytical grade, and deionized (DI) water was used for washing and solution preparation.

\subsection{Preparation of aminosilanized clay}

$3 \mathrm{~g}$ of purified clay (B) were dispersed in water $(300 \mathrm{~mL}$ ) for $24 \mathrm{~h}$, then a solution of 3-aminopropyl-triethoxysilane APTES (3.6 mL dissolved in ethanol/acetic acid (95/5 v/v) was added to the clay suspension dropwise under vigorous stirring and left to proceed for $24 \mathrm{~h}$ at $80^{\circ} \mathrm{C}$. The aminosilanized clay was then washed with water followed by ethanol, in order to remove unreacted moieties. Then dried for $72 \mathrm{~h}$ at $60^{\circ} \mathrm{C}$.

\subsection{Synthesis of clay/polypyrrole-Zinc oxide hybrid material (B-PPy/} $\mathrm{ZnO})$

B-PPy/ZnO hybrid composite was prepared through in situ photopolymerization of $0.1 \mathrm{~g}$ of amino-modified clay, in the presence of pyrrole (0.1 M/100 ethanol), 5 wt.\% of $\mathrm{ZnO}$ and $\mathrm{AgNO}_{3}$ aqueous solution $(0.1 \mathrm{~g}$ in $10 \mathrm{~mL})$ used as a photosensitizer, the suspension was kept under stirring for $10 \mathrm{~min}$. Then the suspension was placed in the glassy vessel below UV-reactor (Spectrolinker 1500) and illuminated at $365 \mathrm{~nm}$ for $3 \mathrm{~h}$. After the end of the reaction, the resulting black precipitate was collected, washed, then dried at $40{ }^{\circ} \mathrm{C}$, the as-obtained material will be hereafter abbreviated (B-PPy-ZnO).

\subsection{Preparation of coatings for corrosion, study. B-PPy/ZnO/Epoxy resin}

Preparation of coatings for corrosion, study. B-PPy/ZnO-Epoxy resin coatings were prepared by dispersing $(1,3,4$, and 5 wt. $\%)$ of B, or B$\mathrm{PPy} / \mathrm{ZnO}$ fillers in $1.7 \mathrm{~g}$ of epoxy resin, then sonicated for $20 \mathrm{~min}$ using a probe sonicator (UP $400 \mathrm{~S}$ ultrasonic processor). The curing agent (Epikure 3223) ( $0.6 \mathrm{~g}$ ) was then added to the mixture. The application of coating was accomplished by the deposition of the mixture on polished carbon steel using a doctor blade (500 $\mathrm{mm}$ thickness). Finally, the asprepared coatings were cured at room temperature for $48 \mathrm{~h}$ before testing.

\subsection{Antibacterial assay}

The proposed B, B-PPy, and B-PPy/ZnO were incorporated in the agar medium to test for antimicrobial efficacy. The minimal inhibitory concentration (MIC), defined as the lowest concentration of each compound that inhibits the visible growth of bacteria after overnight incubation, were determined by the nutrient agar dilution method outlined by Andrews (2001). B, B-PPy, and B-PPy/ZnO materials were added individually to molten nutrient agar (CMOOO3 Oxoid, Hampshire, England) at $60^{\circ} \mathrm{C}$, as these compounds are heat stable at this temperature. The final concentrations of each compound in the medium ranged from 1.25 to $0.00975 \mathrm{mg} \mathrm{ml}^{-1}$. This solution was vigorously shaken while hot to allow mixing and even distribution of each component. Agar medium containing the materials were poured into culture plates and allowed to cool down and solidify. Escherichia coli inoculum was prepared from an $18 \mathrm{~h}$ bacterial culture. Four spots, each corresponding to $10 \mu \mathrm{L}(104$ $\mathrm{CFU} / \mathrm{spot}$ ) of the bacteria, was used to inoculate the prepared agar plates and incubated at $37{ }^{\circ} \mathrm{C}$ for $18-24 \mathrm{~h}$. Negative and positive control with our without bacterial inoculum, respectively, were conducted with each experiment.

\subsection{Cytotoxicity assay}

Cytotoxicity assay was carried out on the A549 (ATCC $\left(\right.$ CCL-185 ${ }^{\mathrm{TM}}$ ) cell line. Cells were cultured in Ham's Kaighn's (F-12 K) Medium supplemented with $10 \%$ Fetal Bovine Serum (FBS) and $1 \%$ penicillinstreptomycin $(\mathrm{P} / \mathrm{S})$. They were maintained in a humidified $37{ }^{\circ} \mathrm{C}$ incubator with $5 \%$ carbon dioxide $\left(\mathrm{CO}_{2}\right)$ until they reached $90 \%$ confluent. Cells were trypsinized then pelleted by centrifugation at $200 \mathrm{~g}$ for $5 \mathrm{~min}$. The pelleted cells were re-suspended in media then counted. A total of 10,000 cells were seeded per well of a 96 well plate for $14 \mathrm{~h}$. Then the media was changed with media containing the material for $24 \mathrm{~h}$. The material was prepared as follows; stock concertation of $1 \mathrm{mg} \mathrm{ml}^{-1}$ of each of the Blank (B), (B-PPY), and B-PPy/ZnO was prepared in cell culture medium then sterilized under UV light for $15 \mathrm{~min}$. For each of the materials, a serial dilution of $0.04,0.05,0.06$, and $0.07 \mathrm{mg} / \mathrm{mL}$ was prepared in the medium.

MTT viability assay (CyQUANTTM MTT Cell Proliferation Assay Kit, Invitrogen, V13154) was conducted according to the manufactures' protocol. Statistical analysis was performed using GraphPad Prism 6 software. Data were analyzed using Two-way-ANOVA with Tukey's post-hoc test. A p-value of less than 0.05 was considered statistically significant. 


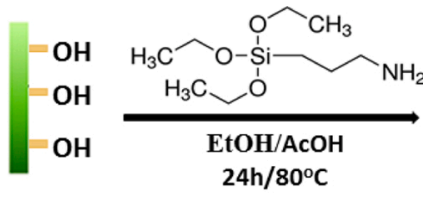

Pure bentonite (B)

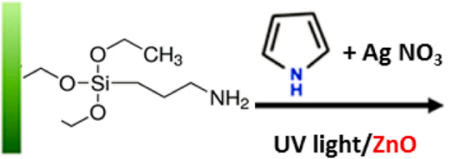

Silanized bentonite (B)

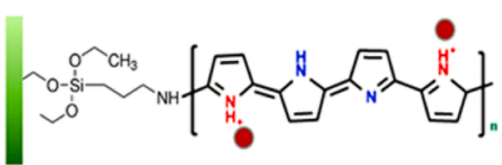

B-PPy/Zno hybrid material

Fig. 1. Surface modification of clay by 3-aminopropyl-triethoxysilane followed by in situ photopolymerization of pyrrole in the presence of zinc oxide.

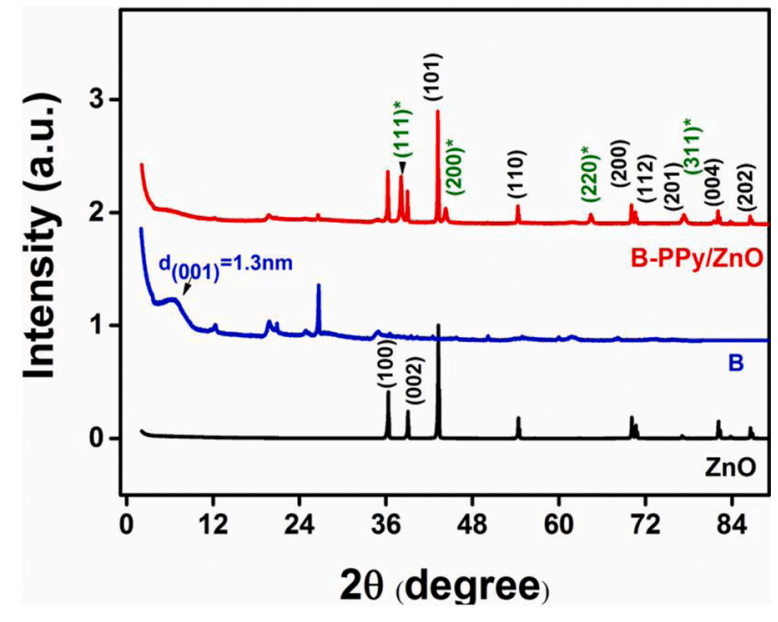

Fig. 2. XRD pattern of ZnO, B, and B-PPy/ZnO samples.

\subsection{Characterization}

XPS spectra were obtained using an Axis ultra DLD instrument fitted with a monochromated $\mathrm{Al} \mathrm{K \alpha} \mathrm{X}$-ray source and the elemental atomic concentrations were calculated from the XPS peak areas and the corresponding Scofield sensitivity factors. XRD analyses were achieved using a PANalytical instrument with $\mathrm{Co} \mathrm{K} \alpha\left(1.789 \mathrm{~A}^{\circ}\right)$. The fracture surfaces of the prepared coating and samples were studied using a Nova Nano SEM 450 Scanning Electron Microscope. Corrosion study was performed in a $\mathrm{NaCl}$ solution (3.5 wt. \%) at room temperature using electrochemical impedance spectroscopy (EIS) at open circuit potential (OCP) using a Gamry Ref 3000 potentiostat supported with Echem analyst software. The frequency range was from $10^{5}$ to $10^{-2} \mathrm{~Hz}$ and a wave amplitude of $\pm 5 \mathrm{mV}$.

\section{Results and discussion}

\subsection{Preparation of clay/polypyrrole with embedded $\mathrm{ZnO}$ nanoparticles}

Fig. 1 demonstrates the preparation steps of B-PPy/ZnO hybrid materiel via two steps. B was first modified using 3-aminopropyltriethoxysilane, the resulting silanized clay was then subjected to in situ polymerization of pyrrole using $\mathrm{AgNO}_{3}$ as a photosensitizer and in the presence of zinc oxide nanoparticles, under UV light exposure.

\subsection{Morphology and structure}

Fig. 2 displays the XRD patterns of $\mathrm{ZnO}, \mathrm{B}$, and B-PPy/ZnO composite. The basal distance of bentonite could be observed at a diffraction angle less than 10 degrees, and according to Bragg's equation, the basal
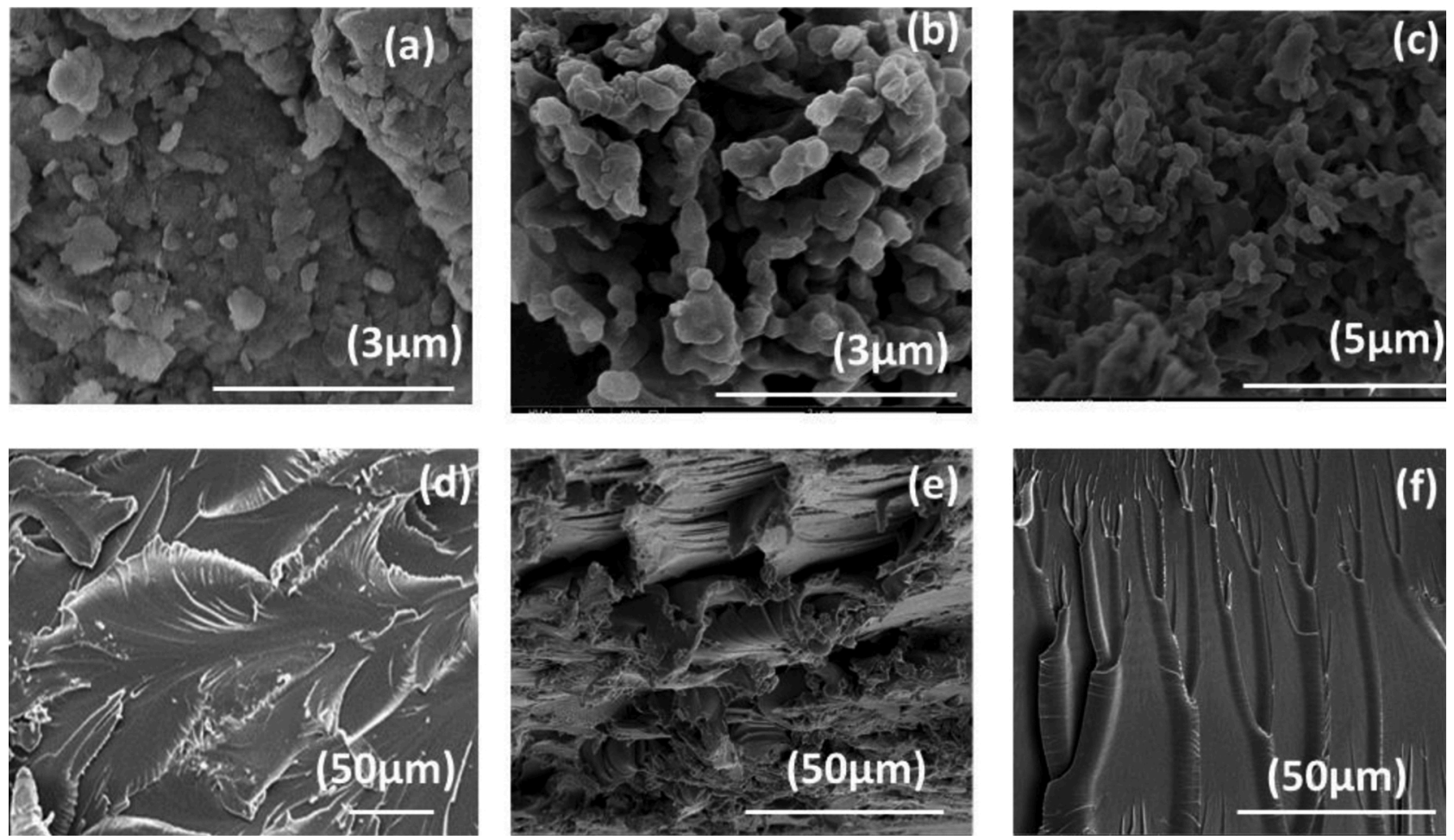

Fig. 3. SEM micrographs of B (a) and B-PPy/ZnO (b-c) at different magnifications and the microstructure of the fractured surface of the epoxy (d), with B (e) or B$\mathrm{PPy} / \mathrm{ZnO}$ (f). 


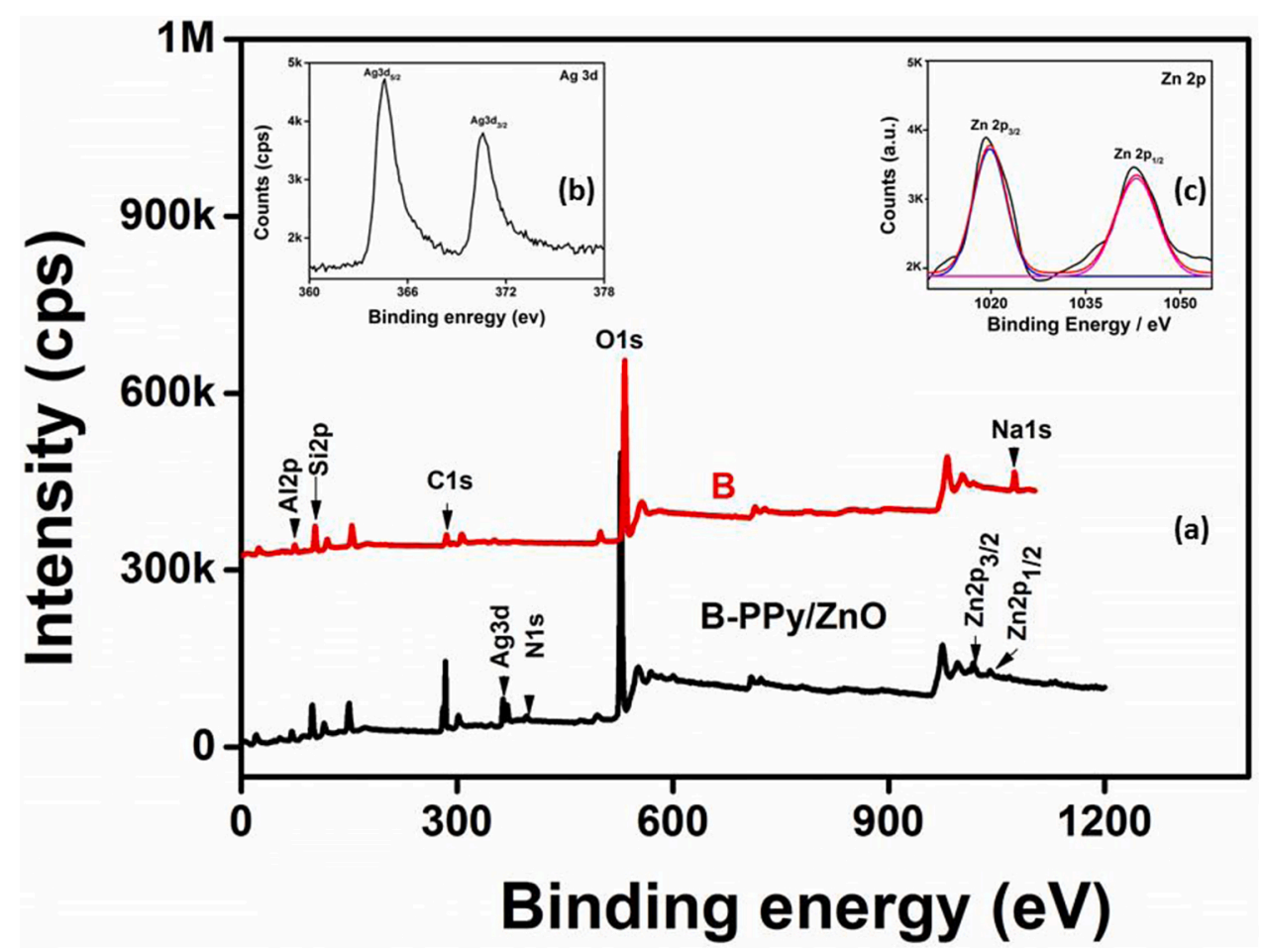

Fig. 4. XPS survey spectra for $\mathrm{B}$ and B-PPy/ZnO materials (a); high-resolution Ag3d (b) and Zn2p from B-PPy/ZnO (c).

Table 1

XPS-determined surface chemical composition of B and B-PPY/ZnO hybrid materials.

\begin{tabular}{|c|c|c|c|c|c|c|c|c|c|c|c|}
\hline Materials & $\mathrm{Si}$ & $\mathrm{Al}$ & $\mathrm{O}$ & $\mathrm{C}$ & $\mathrm{N}$ & $\mathrm{N}\left(\mathrm{NO}_{3}\right)$ & $\mathrm{Ag}$ & $\mathrm{Zn}$ & $\mathrm{Na}$ & $\mathrm{K}$ & $\mathrm{Ca}$ \\
\hline B & 19.9 & 7.9 & 60.3 & 8.50 & - & - & - & & 2.80 & 0.11 & 0.50 \\
\hline B-PPy/ZnO & 14.2 & 4.7 & 35.3 & 33.0 & 4.98 & 0.10 & 1.20 & 6 & - & 0.30 & 0.30 \\
\hline
\end{tabular}

distance d (001) was found to be equal to $1.3 \mathrm{~nm}$. It is essential to note that after the in situ photopolymerization of pyrrole on the bentonite modified clay, the basal distance was increased due to the exfoliation occurred for the $\mathrm{B}-\mathrm{PPy} / \mathrm{ZnO}$ composite, as previously reported [25], as a result of the deep penetration and growth of polypyrrole chains within its inter-layer spaces of the bentonite clay.

The B-PPy/ZnO composite pattern showed the characteristic diffraction peaks of the hexagonal wurtzite structure of $\mathrm{ZnO}$ (JCPDS file no.36-1451) as well as the Ag NPs in the metallic state (JCPDS file no. 00-001-1164). The absence of the diffraction peak corresponding to PPy (at about $24^{\circ}$ ) indicates its amorphous character, as previously reported [25].

Fig. 3(a-c) shows the morphologies of B and B-PPy/ZnO at different magnification, as well as the microstructure of fractured surface of the pure and B-PPy/ZnO, filled epoxy in Fig. 3(d-f).

One can note that unmodified bentonite consists of densely packed grains (Fig. 3a). The morphology of the B-PPy/ZnO at different magnifications was displayed in (Fig. 3b-c), and reveals the PPy typical morphology, as cauliflower like-structure [36]. However, the clay particles were not observed at the surface of the B-PPy/ZnO composite. This indicates that during the in-situ photopolymerization, the clay particles were fully coated by the PPy polymer and $\mathrm{ZnO}$ nanoparticles, which can be facilitated by chemical interaction between the PPy and the amino-modified clay surface. PPy is chemically grafted to the surface of amino-modified clay. A similar interaction between the amine group of aniline and the amino-modified clay was previously reported [37].
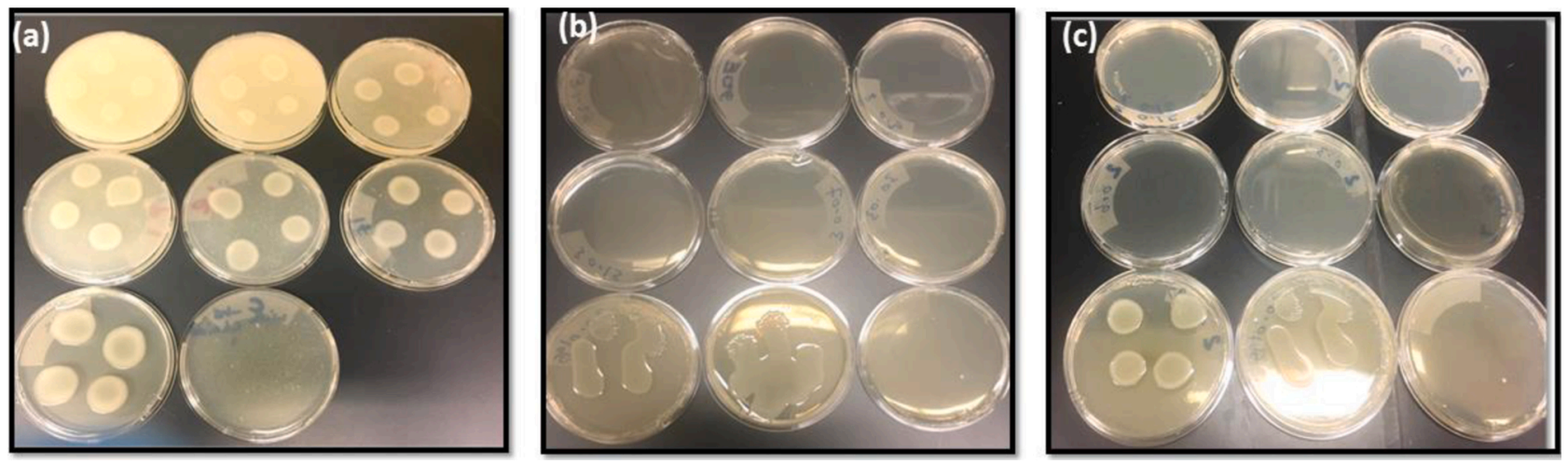

Fig. 5. Digital photographs of the antimicrobial efficacy of B (a), B-PPy (b), and B-PPy/ZnO (c) against Escherichia coli. 
Fig. 3d displays fracture surfaces for pure epoxy. It shows a smooth river-like structure as previously reported [14], a similar structure was noted for the B-epoxy as well, most likely due to weak interaction and dispersion of the untreated bentonite nanoclay within the epoxy matrix. However, a radical change was noted in the morphology of $\mathrm{B}-\mathrm{PPy} / \mathrm{ZnO}$ filled epoxy, a fibril network like-structure was observed; this network structure is most probably induced by a strong interface interaction between B-PPy/ZnO and the used epoxy resin.

\subsection{XPS surface analysis}

Fig. 4a displays the XPS survey of B and B-PPy/ZnO. The main peaks are Si2p (103 eV), Al2p (74 eV), Na1s (1072 eV), O1s (531 eV), C1s (285 eV), N1s (400-402 eV), Ag3d (368-374 eV) and Zn2p (1022-1045 eV).

(A)

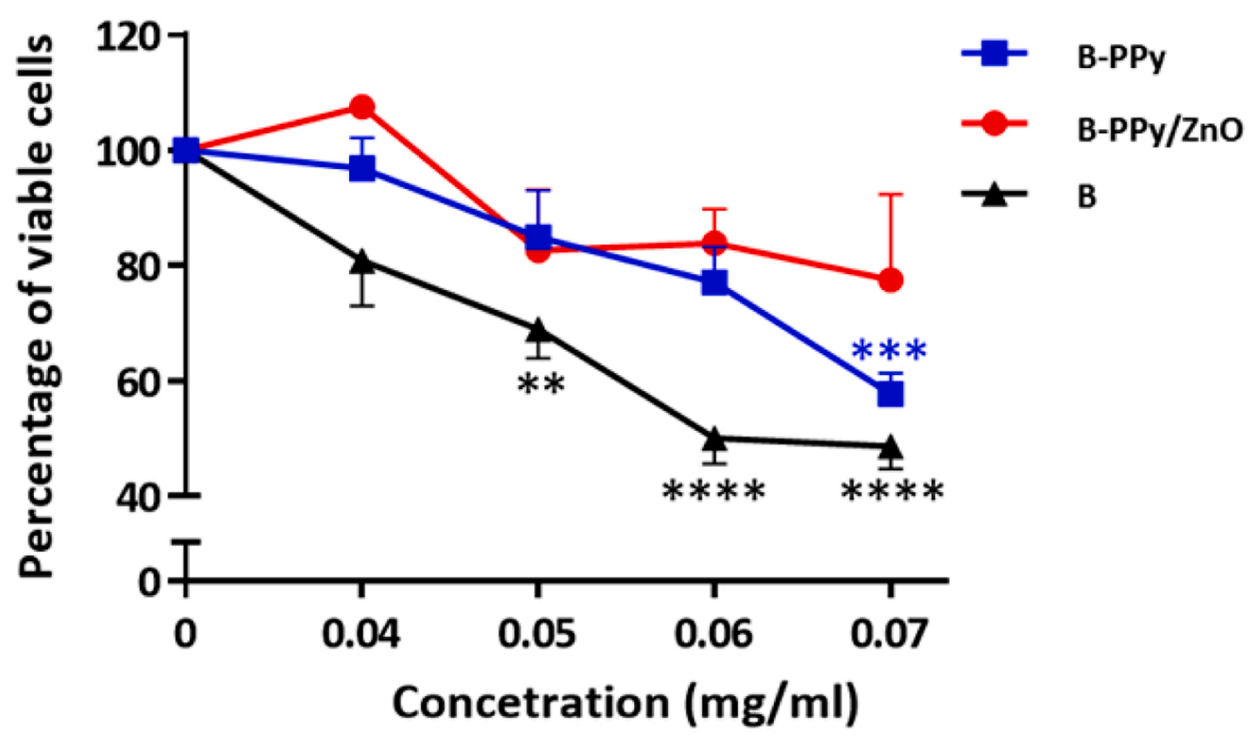

(B)
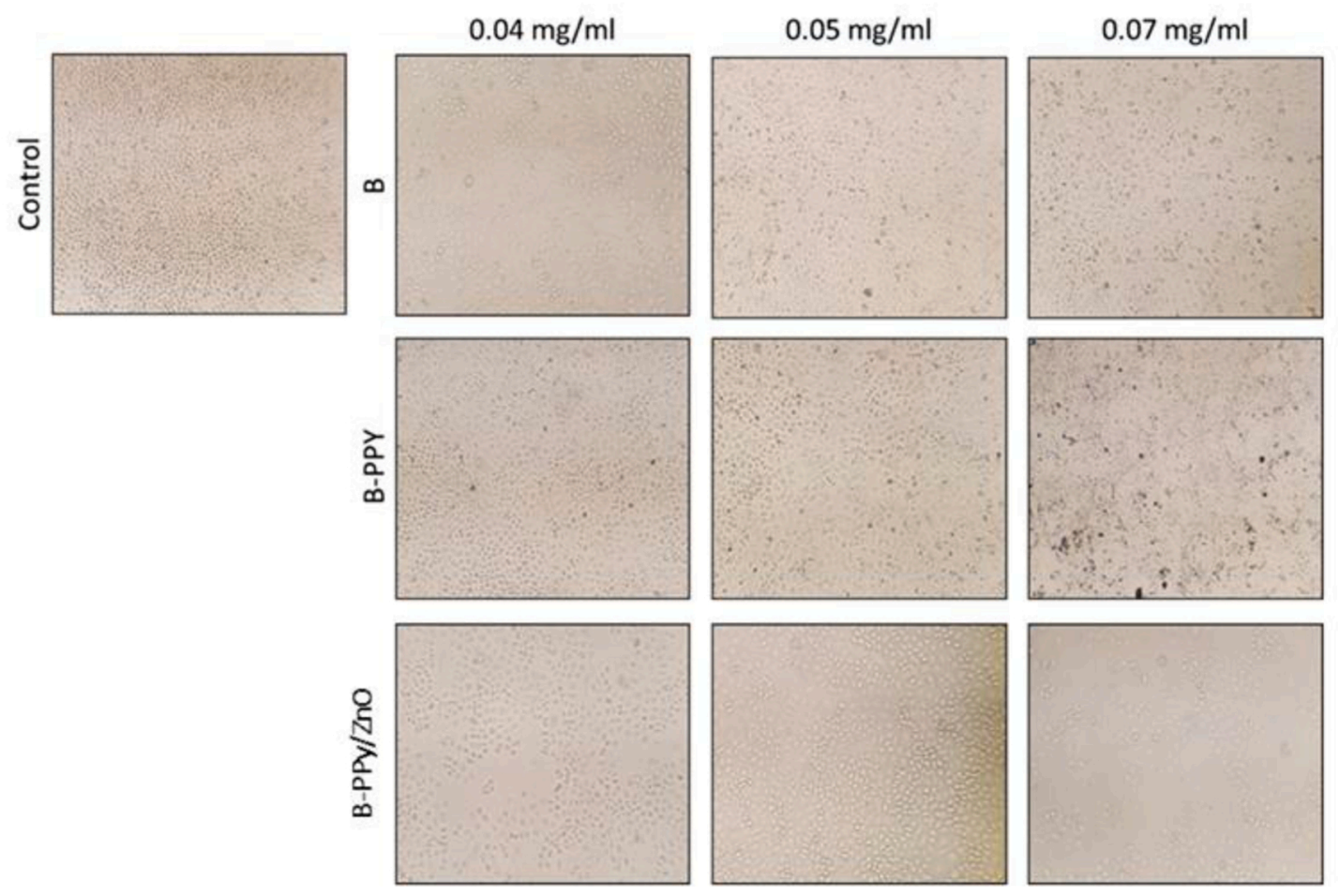

Fig. 6. A549 cells were exposed to 0.04, 0.05, 0.06, and $0.07 \mathrm{mg} / \mathrm{mL}$ of either Blank (B), (B-PPY) and B-PPy/ZnO for 24 h. (A). MTT viability assay showed that B$\mathrm{PPy} / \mathrm{ZnO}$ was the least toxic as it did not cause a significant reduction in cell viability. (B). Optical microscopy images of A549 exposed to different concertation of the material. 
The B-PPy/ZnO shows an increase in the relative intensity of $\mathrm{C} 1 \mathrm{~s}$, but more importantly, the N1s peak assigned to the pyrrole group borne by the aminosilane-coupling agent. After polymerization, a sharp doublet of Ag3d and $\mathrm{Zn} 2 \mathrm{p}$ is visible in the B-PPy/ZnO sample, indicating that the process is successful. The Ag3d and Zn2p high-resolution spectra of BPPy/ZnO are displayed in Fig. 4(b) and (c), respectively, Ag3d peaks are

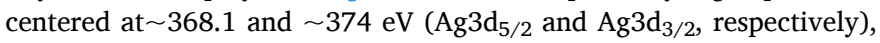
confirming that metallic state of silver in the $\mathrm{Ag}$ nanoparticles generated during the UV-induced polymerization process, for the $\mathrm{Zn} 2 \mathrm{p}$ the two peaks centered at 1022.3 and $1045.1 \mathrm{eV}$ are similar to the reported peaks of $\mathrm{Zn} 2 \mathrm{p}_{3 / 2}$ and $\mathrm{Zn} 2 \mathrm{p}_{1 / 2}$. This is supported by quantitative data reported in Table 1.

Table 1 reports the chemical composition of untreated and modified clay sample surfaces. Upon photopolymerization, the sodium is completely removed. The silanization provides a much greater extent of C, N, Zn, and Ag.

\subsection{Potential antibacterial application}

The proposed material is fascinating because it is performed within a relatively short period and particularly yields polypyrrole with welldispersed $\mathrm{ZnO}$ and $\mathrm{Ag}$ NPs. it is possible to interrogate the performances of these heterostructures as non-toxic and antibacterial coating materials. All three material B, B-PPy and B-PPy/ZnO were incorporated in agar medium to test for antimicrobial efficacy against Escherichia coli inoculums. As illustrated in Fig. 5 the minimum inhibitory concentration for both (B-PPy) and (B-PPy/ZnO) was found to be $0.03 \mathrm{mg} / \mathrm{mL}$. On the other hand, purified bentonite showed bacterial growth at all concentrations. All negative control were negative and all positive control (Nutrient agar plus bacteria) were found to be positive. This simple test shows that with well dispersed $\mathrm{ZnO}$ and Ag NPs over the bentonite polypyrrol template are highly effective in imparting excellent antibacterial properties to a low cost natural bentonite (Fig. 6).

\subsection{Cell Cytotoxicity experiment of generated materials}

In order to interrogate cytotoxicity of the prepared hybrid materials, A549 cells were exposed to serial dilutions of each material (Fig. 6). The minimum concertation was chosen based on the antimicrobial data. MTT viability test showed that B reduced cell viability to $80 \%$ at 0.04 $\mathrm{mg} / \mathrm{mL}$. This decrease was further exaggerated at higher concentration reaching to around $50 \%$ at $0.07 \%$ (p values of 0.0082 at 0.05 and
$<0.0001$ at $0.06 \mathrm{mg} / \mathrm{mL}$ and $0.07 \mathrm{mg} / \mathrm{mL}$ when compared to $0 \mathrm{mg} / \mathrm{mL}$ ) (Fig. 6B). B-PPy showed better results at concertation of $0.04-0.06 \mathrm{mg} /$ $\mathrm{mL}$. However, it significantly reduced cell viability at $0.07 \mathrm{mg} / \mathrm{mL}$ (pvalue of 0.0003 ). B-PPy/ZnO was the least toxic as it did not cause any significant reduction in cell viability even at higher concentrations (pvalue of 0.08 ) (Fig. 6A).

\subsection{Anticorrosion measurement}

The anticorrosive merits of the as-synthesized coatings with different content of PPy/ZnO (0, 1, 2, 3, 4, and 5 wt.\%) were investigated using electrochemical impedance spectroscopy technique (EIS) with the aid of Gamry 3000 (potentiostat/Galvanostate/ZRA, USA) with the threeelectrode system. The as-prepared coatings were used as the working electrode, whereas the counter and reference electrodes were represented by graphite and $\mathrm{Ag} / \mathrm{AgCl}$, respectively. EIS measurements at OCP were commenced in saline solution $(3.5 \mathrm{wt} . \% \mathrm{NaCl})$ after attaining steady-state potential, and the frequency range was from $10^{5}$ to $10^{-2} \mathrm{~Hz}$ and an AC amplitude of $\pm 5 \mathrm{mV}$ at $25^{\circ} \mathrm{C}$.

\section{Evaluation of anti-corrosion performance}

EIS is a widely used potent technique to elucidate the anticorrosion performance of epoxy coatings due to its non-destructive and appropriates features $[38,39]$. The influence of the $\mathrm{PPy} / \mathrm{ZnO}$ content on the corrosion protection efficiency of the epoxy coating was evaluated by the EIS parameters obtained from the fitting of the EIS measured data using electrical equivalent circuits. Fig. 7 depicts the two types of equivalent electrical circuits used for EIS analysis; One is two, and the other is three-time constants [40]. Additionally, a Warburg diffusion element was included to express the mass transfer at the low-frequency domain. The EIS parameters, derived from fitting the experimental results using the two equivalent circuits shown in Fig. 7, are listed in Table 2. $R_{s}$ and $R_{\text {coat }}$ are the solution and the coating resistance, respectively. Meanwhile, $R_{c t}$ represents the charge transfer resistance, as seen in Fig. 7. Nevertheless, the resistor $R_{\text {inter }}$ in the three-time constant equivalent circuit corresponds to the formation of an interfacial layer with properties varied from those of coating and bare metal. $C P E_{1}, C P E_{2}$, and $C P E_{3}$ related to the admittance of the constant phase elements. Additionally, $W$ is a Warburg diffusion coefficient. It worth mentioning that the $C P E$ could be calculated theoretically by the equation below [41].

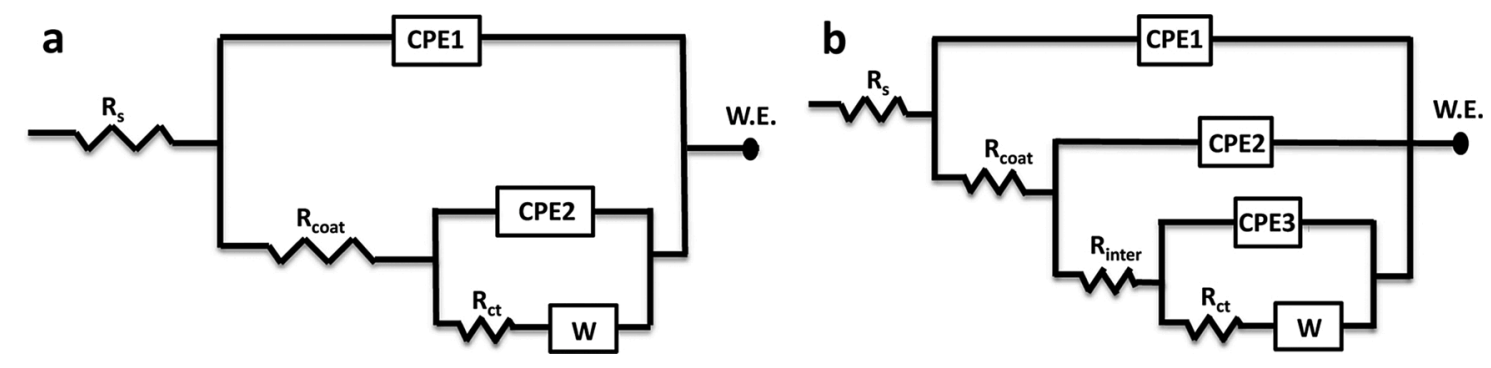

Fig. 7. Electrochemical electric equivalent circuits maintained for analysis of the measured data.

Table 2

EIS parameters for epoxy coating without and with $(0,1,2,3,4,5) \mathrm{wt} . \%$ of PPy/ZnO in saline solution at room temperature.

\begin{tabular}{|c|c|c|c|c|c|c|c|c|c|c|c|}
\hline $\begin{array}{l}\text { Wt. } \\
\%\end{array}$ & $\begin{array}{l}R s, \Omega \\
\mathrm{cm}^{-2}\end{array}$ & $\begin{array}{l}R_{\text {coat }}, \mathrm{M} \Omega \\
\mathrm{cm}^{-2}\end{array}$ & $\begin{array}{l}C P E_{1} \mu \mathrm{s}^{\mathrm{n}} \Omega^{-1} \\
\mathrm{~cm}^{-2}\end{array}$ & $n_{1}$ & $\begin{array}{l}R_{\text {inter }} \mathrm{M} \Omega \\
\mathrm{cm}^{-2}\end{array}$ & $\begin{array}{l}C P E_{2} \times 10^{-3} \mu \mathrm{s}^{\mathrm{n}} \Omega^{-1} \\
\mathrm{~cm}^{-2}\end{array}$ & $n_{2}$ & $\begin{array}{l}R_{\mathrm{ct}} \mathrm{M} \Omega \\
\mathrm{cm}^{-2}\end{array}$ & $\begin{array}{l}C P E_{3} \times 10^{-3} \mu \mathrm{s}^{\mathrm{n}} \Omega^{-1} \\
\mathrm{~cm}^{-2}\end{array}$ & $n_{3}$ & $\begin{array}{l}\mathrm{W} \mu \mathrm{s}^{\mathrm{n}} \Omega^{-1} \\
\mathrm{~cm}^{-2}\end{array}$ \\
\hline 0 & 13.5 & 0.213 & 73.2 & 0.893 & - & - & $\longrightarrow$ & 1.242 & 2061 & 0.784 & 173.6 \\
\hline 1 & 45.2 & 0.968 & 24.3 & 0.816 & - & - & - & 11.57 & 113.7 & 0.716 & 114.2 \\
\hline 2 & 26.7 & 1.14 & 3.71 & 0.798 & 65.83 & 70.91 & 0.649 & 127 & 30.97 & 0.615 & 54.91 \\
\hline 3 & 37.1 & 3.37 & 1.08 & 0.681 & 105.1 & 38.79 & 0.607 & 312 & 11.26 & 0.845 & 1.723 \\
\hline 4 & 19.6 & 9.85 & 0.62 & 0.643 & 250.3 & 17.87 & 0.528 & 869 & 0.02 & 0.514 & 2.469 \\
\hline 5 & 14.8 & 2.88 & 3.37 & 0.619 & 419.5 & 6.785 & 0.492 & 723 & 0.06 & 0.758 & 8.691 \\
\hline
\end{tabular}


$\frac{1}{Z_{C P E}}=Y^{*}(j \omega)^{n}$

Where $Y$ equal the admittance (s. $\Omega^{-1} \cdot \mathrm{cm}^{-1}$ ), $j$ is an imaginary number $(-1)^{1 / 2}, \omega$ is the angular frequency of the AC signal $\left(\operatorname{rad~s}^{-1}\right), n$ is the CPE roughness and its value in range $0-1$. The $C P E$ approach to the ideal capacitor behavior when $n=1$ and the CPE seem to be similar to a resistor attitude when $n=0$ [42]. It worth mentioning that the double-layer capacitance $\left(C_{\mathrm{dl}}\right)$ can be derived the equation below [43].
$C_{d l}=\sqrt[n]{\frac{Y}{R_{x}^{*}(n-1)}}$

Where $Y$ and $n$ are admittance constant and empirical exponent of $C P E$, respectively, and $R_{\mathrm{x}}$ represents the charge transfer resistance or interfacial resistance or coating resistance.

Figs. 8 and 9 represent the EIS Nyquist and Bode curves, respectively, for epoxy coating specimens with $(0,1,2,3,4$, and 5 wt.\%) loading amount of $\mathrm{PPy} / \mathrm{ZnO}$ immersed in $3.5 \mathrm{wt} \% \mathrm{NaCl}$ solution at room
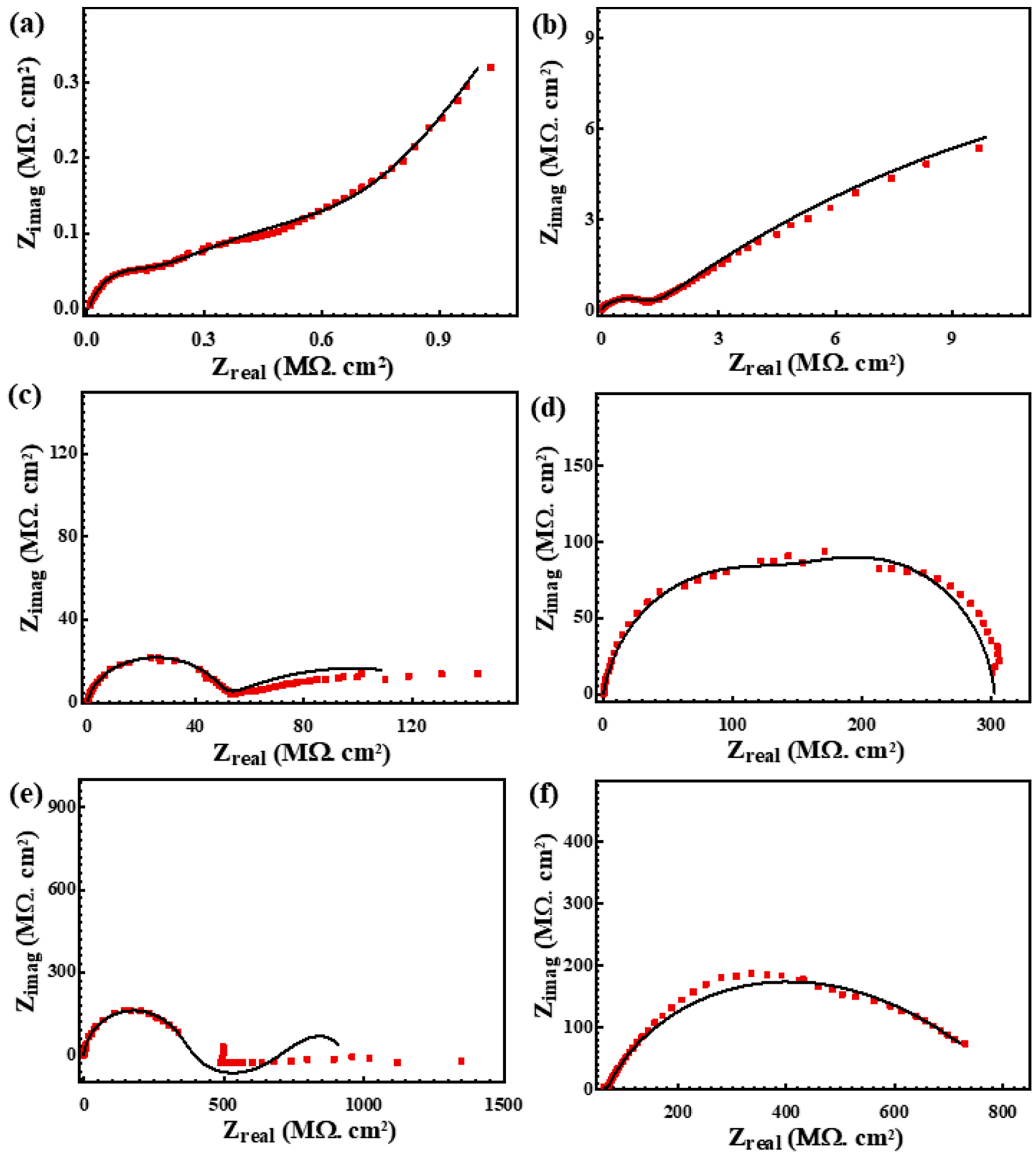

Fig. 8. EIS Nyquist plots measured (dotted) fitted (line) of coated steel specimens containing 0 wt.\% (a), 1 wt.\% (b), 2 wt.\% (c), 3 wt.\% (d), 4 wt.\% (e), and 5 wt.\% (f) of PPy/ZnO immersed in saline solution. 
temperature. It can be noticed that the measured EIS data for the pure epoxy coating and the lowest loading amount of PPy/ZnO (1 wt.\%) were analyzed using a two-time constant equivalent circuit which neglects the effect of adding PPy/ZnO despite the tremendous increment in the charge transfer resistance from 1.242 to $11.57 \mathrm{M} \Omega \mathrm{cm}^{-2}$ and the coating resistance from 213 to $968 \mathrm{k} \Omega \mathrm{cm}^{-2}$. This is attributed to lessening the pinholes defects in the coating matrix by filling the pores of the coating/ metal interface with the $\mathrm{PPy} / \mathrm{ZnO}$, which prohibits the corrosive ions attack [44]. Meanwhile, the three-time constant equivalent circuit was suggested for fitting the EIS data for 2, 3, 4 and $5 \mathrm{wt} \%$ of PPy/ZnO composite coatings as the interfacial resistance $\left(R_{\text {inter }}\right)$ was continuously increased from $65.83-419.5 \mathrm{M} \Omega \mathrm{cm}^{-2}$ with increasing the doping amount of the filler This is attributed to the alteration of $\mathrm{ZnO}$ nanoparticles into $\mathrm{Zn}^{+2}$ ions which act as synergistic inhibitive species against the aggressive ions [43]. and therefore, hinders the diffusion of $\mathrm{Cl}$ - ions along with the coating layer, as it can be notified in the Warburg diffusion coefficient values. It is worth mentioning that the coating resistance values $\left(R_{\text {coat }}\right)$ were continuously increased, reaching the maximum value $\left(9.85 \mathrm{M} \Omega \mathrm{cm}^{-2}\right)$ at $4 \mathrm{wt} . \%$ of the epoxy coating nanocomposite. However, a further increase of PPy/ZnO content (5 wt.\%), leads to a discernible dropdown in the $R_{\text {coat }}$ value $2.88 \mathrm{M} \Omega \mathrm{cm}^{-2}$. This is attributed to the agglomeration of the filler additives, which could produce defects in the coating matrix, such as pinholes or pores [45]. Also, the $R_{\mathrm{ct}}$ values were followed the same trend of the $R_{\text {coat }}$ as it was significantly increased with adding different content of $\mathrm{PPy} / \mathrm{ZnO}$ achieving $869 \mathrm{M} \Omega \mathrm{cm}^{-2}$ at $4 \mathrm{wt} . \%$ then a fair drop was witnessed (723 $\mathrm{M} \Omega \mathrm{cm}^{-2}$ ) at the optimum concentration of $\mathrm{PPy} / \mathrm{ZnO}$ nanocomposite. It is worth mentioning that the $C P E$, which consider as a proportional
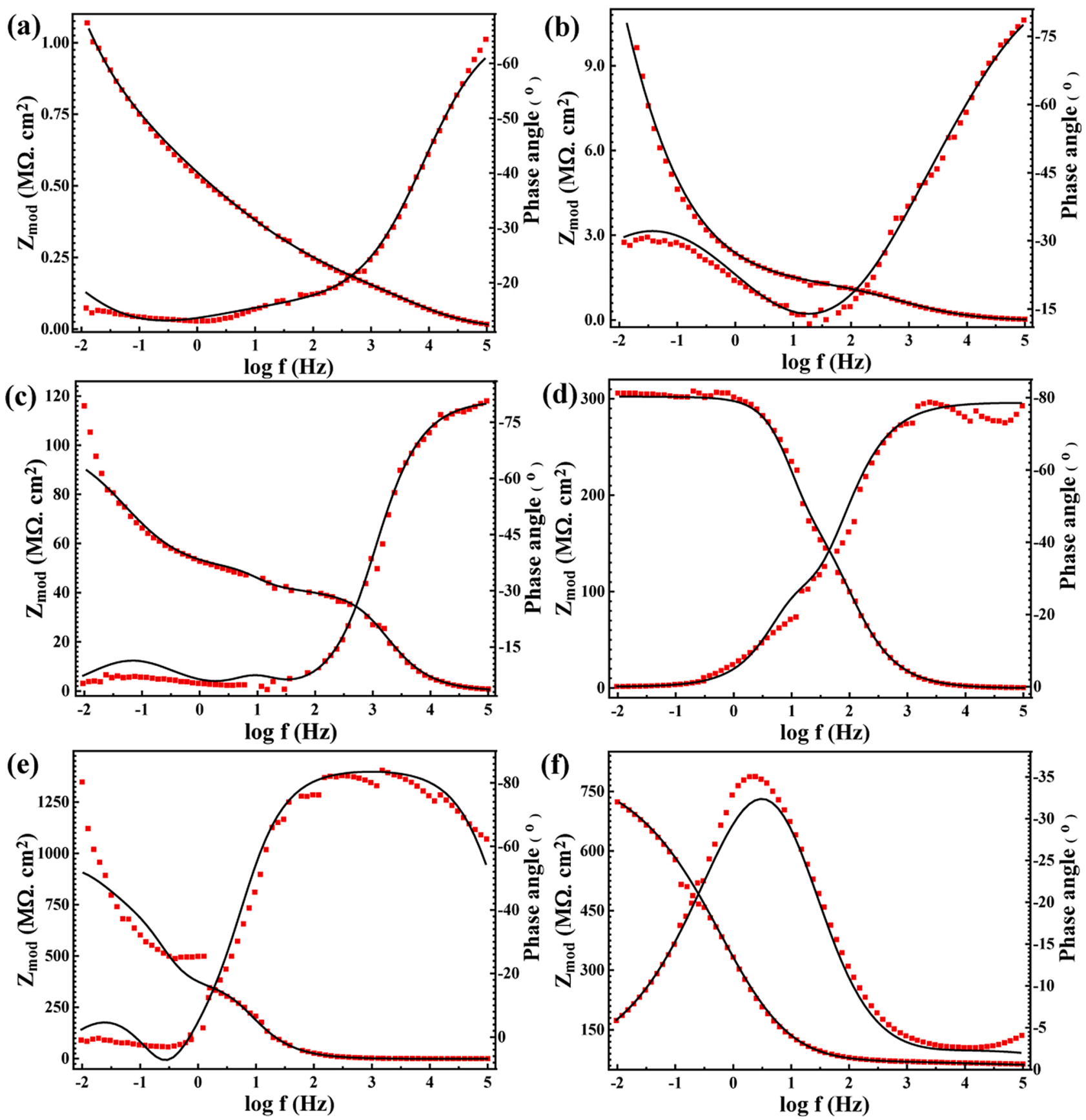

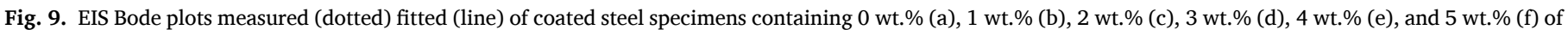
$\mathrm{PPy} / \mathrm{ZnO}$ immersed in saline solution. 
factor for the $C_{\mathrm{dl}}$ is inversely proportional to the resistances mentioned above [46]. As the high resistance values, the more sluggish charges transfer, as seen in Table 2. Also, the values of the Warburg diffusion coefficient were consistently reduced with increasing the PPy/ZnO content as it drops down from 173 to $2.469 \mu \mathrm{s}^{\mathrm{n}} \Omega^{-1} \mathrm{~cm}^{-2}$ for the plain epoxy coating reaching to $4 \mathrm{wt} . \%$ of $\mathrm{PPy} / \mathrm{ZnO}$, respectively. It increases to $8.691 \mu \mathrm{s}^{\mathrm{n}} \Omega^{-1} \mathrm{~cm}^{-2}$ at $5 \mathrm{wt} . \%$ of filler content. Beside the aforementioned reasons the electrostatic interaction between the PPy/ZnO agglomerates at high concentrations, high charge transfer resistance substantially affects on charges attraction forces which exist on the $\mathrm{PPy} / \mathrm{ZnO}$ and facilitate the diffusion of the aggressive ions [47].

\section{Conclusion}

In this work, simple and cost-effective bentonite intercalated with polypyrrole Zinc oxide and silver nanocomposite (B-PPy/ZnO) hybrid material was prepared via in situ photopolymerization of pyrrole. The later was used as filler as eco-friendly, anticorrosive and antibacterial coating for carbon steel. The corrosion resistance efficiency study of B$\mathrm{PPy} / \mathrm{ZnO}$ composite incorporated with epoxy matrix, was carried out in $3.5 \% \mathrm{NaCl}$ solution. Highest charge transfer resistance value was noted in presence of $\mathrm{B}-\mathrm{PPy} / \mathrm{ZnO} 4 \mathrm{wt} \%$ of added filler, and it reached $(9.85 \mathrm{M} \Omega$ $\mathrm{cm}^{-2}$ ) compared to $0.213 \mathrm{M} \Omega \mathrm{cm}^{-2}$ in presence of pure epoxy. Cytotoxicity assay was carried out on A549 epithelial cell line. Moreover, B$\mathrm{PPy} / \mathrm{ZnO}$ showed a reduction in Escherichia coli bacterial growth by $\sim 86$ $\%$ with a minimum inhibitory concentration of $0.03 \mathrm{mg} / \mathrm{mL}$. The results obtained herein will open new routes to the preparation of high added value anticorrosion and antibacterial coatings.

\section{Author statement}

K. Jlassi conceived the idea and contributed to the interpretation of data, and wrote the manuscript. M. H. Sliem, and A.M. Abdullah designed the corrosion experiments and data analysis, F.M. Benslimane and N. O. Eltaib contributed to viability assay and the antibacterial application respectively. All authors reviewed the manuscript.

\section{Declaration of Competing Interest}

All authors declare no conflict of interest.

\section{Acknowledgement}

This study was made possible by student grant QUST-1-CAM-2019-9 awards, from Qatar University. The findings made herein are solely the responsibility of the authors.

\section{References}

[1] D.-Y. Xie, D. Qian, F. Song, X.-L. Wang, Y.-Z. Wang, A fully biobased encapsulant constructed of soy protein and cellulose nanocrystals for flexible electromechanical sensing, ACS Sustain. Chem. Eng. 5 (2017) 7063-7070.

[2] S.K. Karan, S. Maiti, A.K. Agrawal, A.K. Das, A. Maitra, S. Paria, A. Bera, R. Bera, L. Halder, A.K. Mishra, Designing high energy conversion efficient bio-inspired vitamin assisted single-structured based self-powered piezoelectric/wind/acoustic multi-energy harvester with remarkable power density, Nano Energy 59 (2019) $169-183$.

[3] Y. Zhang, S. Yun, C. Wang, Z. Wang, F. Han, Y. Si, Bio-based carbon-enhanced tungsten-based bimetal oxides as counter electrodes for dye-sensitized solar cells, J. Power Sources 423 (2019) 339-348.

[4] M. Zhu, Y. Wang, L. Long, X. Fu, G. Sui, X. Yang, An optimal carbon fiber interlayer integrated with bio-based gel polymer electrolyte enabling trapping-diffusionconversion of polysulfides in lithium-sulfur batteries, Chem. Eng. J. 370 (2019) $1068-1076$.

[5] H. Cui, N. Pan, W. Fan, C. Liu, Y. Li, Y. Xia, K. Sui, Ultrafast fabrication of gradient nanoporous all-polysaccharide films as strong, superfast, and multiresponsive actuators, Adv. Funct. Mater. 29 (2019), 1807692.

[6] M. Zhu, R. Xiong, C. Huang, Bio-based and photocrosslinked electrospun antibacterial nanofibrous membranes for air filtration, Carbohydr. Polym. 205 (2019) 55-62.
[7] S. Zheng, D.A. Bellido-Aguilar, Y. Huang, X. Zeng, Q. Zhang, Z. Chen, Mechanically robust hydrophobic bio-based epoxy coatings for anti-corrosion application, Surf. Coat. Technol. 363 (2019) 43-50.

[8] F.J. Ruiz-Cabañas, C. Prieto, R. Osuna, V. Madina, A.I. Fernández, L.F. Cabeza, Corrosion testing device for in-situ corrosion characterization in operational molten salts storage tanks: A516 Gr70 carbon steel performance under molten salts exposure, Sol. Energy Mater. Sol. Cells 157 (2016) 383-392.

[9] S. Zhou, H. Lv, Y. Wu, Degradation behavior of concrete under corrosive coal mine environment, Int. J. Min. Sci. Technol. 29 (2019) 307-312.

[10] A.A. Javidparvar, R. Naderi, B. Ramezanzadeh, Manipulating graphene oxide nanocontainer with benzimidazole and cerium ions: application in epoxy-based nanocomposite for active corrosion protection, Corros. Sci. 165 (2020), 108379.

[11] Y. Pan, C. Chen, D. Wang, D. Huang, Dissolution and precipitation behaviors of silicon-containing ceramic coating on $\mathrm{Mg}-\mathrm{Zn}-\mathrm{Ca}$ alloy in simulated body fluid, Colloids Surf. B Biointerfaces 122 (2014) 746-751.

[12] M. Kiari, R. Berenguer, F. Montilla, E. Morallón, Preparation and characterization of Montmorillonite/PEDOT-PSS and Diatomite/PEDOT-PSS Hybrid materials. study of electrochemical properties in acid medium, J. Compos. Sci. 4 (2020) 51.

[13] M.B.H. Al-Behadili, A. Shah-Hosseini, A. Mohebinia, M. Eftekhari, Polythiophenecoated cerium oxide nanocomposite for efficient solid-phase extraction of trace levels of Zn $2+$ followed by flame atomic absorption spectrometry, Polym. Bull. 77 (2020) 323-337.

[14] K. Jlassi, S. Chandran, M.A. Poothanari, Mm. Benna-Zayani, S. Thomas, M. M. Chehimi, Clay/polyaniline hybrid through diazonium chemistry: conductive nanofiller with unusual effects on interfacial properties of epoxy nanocomposites, Langmuir 32 (2016) 3514-3524.

[15] A.L. Martinez, L.I. Brugnoni, D.O. Flamini, S.B. Saidman, Immobilization of Zn species in a polypyrrole matrix to prevent corrosion and microbial growth on Ti6Al-4V alloy for biomedical applications, Prog. Org. Coat. 144 (2020), 105650.

[16] S. Javadian, Z. Ahmadpour, A. Yousefi, Polypyrrole nanocapsules bearing quaternized alkyl pyridine in a green self-healing coating for corrosion protection of zinc, Prog. Org. Coat. 147 (2020), 105678.

[17] S. Biswas, D.-K. Kim, I.-W. Nam, M. Choi, J.-H. Bae, H. Kim, Highly conductive and thermally stable nanoparticle-conjugated polymer compounds through environmentally friendly in situ synthesis, Prog. Org. Coat. 142 (2020), 105606.

[18] M.F. Attia, T. Azib, Z. Salmi, A. Singh, P. Decorse, N. Battaglini, H. Lecoq, M. Omastová, A.A. Higazy, A.M. Elshafei, One-step UV-induced modification of cellulose fabrics by polypyrrole/silver nanocomposite films, J. Colloid Interface Sci. 393 (2013) 130-137.

[19] M.F. Attia, N. Anton, I.U. Khan, C.A. Serra, N. Messaddeq, A. Jakhmola, R. Vecchione, T. Vandamme, One-step synthesis of iron oxide polypyrrole nanoparticles encapsulating ketoprofen as model of hydrophobic drug, Int. J. Pharm. 508 (2016) 61-70.

[20] H. Wang, W. Zhang, Y. Ma, G. Fei, H. Wen, L. Sun, Y. Shao, Y.-M. Kang, Phosphorylated polymer/anionic surfactant doped polypyrrole in waterborne epoxy matrix toward enhanced mechanical and chemical resistance, Prog. Org. Coat. 143 (2020), 105634.

[21] Z. Chen, W. Yang, X. Yin, Y. Chen, Y. Liu, B. Xu, Corrosion protection of 304 stainless steel from a smart conducting polypyrrole coating doped with $\mathrm{pH}$ sensitive molybdate-loaded TiO2 nanocontainers, Prog. Org. Coat. 146 (2020), 105750.

[22] K. Jlassi, K. Eid, M.H. Sliem, A.M. Abdullah, M.M. Chehimi, I. Krupa, Rational synthesis, characterization, and application of environmentally friendly (polymer-carbon dot) hybrid composite film for fast and efficient UV-assisted Cd 2 + removal from water, Environ. Sci. Eur. 32 (2020) 1-13.

[23] M. Parit, H. Du, X. Zhang, C. Prather, M. Adams, Z. Jiang, Polypyrrole and cellulose nanofiber based composite films with improved physical and electrical properties for electromagnetic shielding applications, Carbohydr. Polym. (2020), 116304.

[24] K. Jlassi, M.H. Sliem, K. Eid, I. Krupa, M.M. Chehimi, A.M. Abdullah, Novel enzyme-free multifunctional Bentonite/Polypyrrole/Silver nanocomposite sensor for hydrogen peroxide detection over a wide pH range, Sensors 19 (2019) 13.

[25] K. Jlassi, A. Singh, D.K. Aswal, R. Losno, M. Benna-Zayani, M.M. Chehimi, Novel, ternary clay/polypyrrole/silver hybrid materials through in situ photopolymerization, Colloids Surf. A Physicochem. Eng. Asp. 439 (2013) 193-199.

[26] A. Saad, E. Cabet, A. Lilienbaum, S. Hamadi, M. Abderrabba, M.M. Chehimi, Polypyrrole/Ag/mesoporous silica nanocomposite particles: design by photopolymerization in aqueous medium and antibacterial activity, J. Taiwan Inst. Chem. Eng. 80 (2017) 1022-1030.

[27] V.V. Tat'yana, O.N. Efimov, Polypyrrole: a conducting polymer; its synthesis, properties and applications, Russ. Chem. Rev. 66 (1997) 443.

[28] L.P. Júnior, D.Bd.S. Silva, M.F. de Aguiar, C.P. de Melo, K.G. Alves, Preparation and characterization of polypyrrole/organophilic montmorillonite nanofibers obtained by electrospinning, J. Mol. Liq. 275 (2019) 452-462.

[29] K. Jlassi, A.B. Radwan, K.K. Sadasivuni, M. Mrlik, A.M. Abdullah, M.M. Chehimi, I. Krupa, Anticorrosive and oil sensitive coatings based on epoxy/polyaniline/ magnetite-clay composites through diazonium interfacial chemistry, Sci. Rep. 8 (2018) 1-13.

[30] M. Ba, Z.-p. Zhang, Y.-h. Qi, The leaching behavior of phenylmethylsilicone oil and antifouling performance in nano-zinc oxide reinforced phenylmethylsilicone oil-Polydimethylsiloxane blend coating, Prog. Org. Coat. 125 (2018) 167-176.

[31] A.S. Lashkenari, M.T.H. Mosavian, M. Peyravi, M. Jahanshahi, Biofouling mitigation of bilayer polysulfone membrane assisted by zinc oxide-polyrhodanine couple nanoparticle, Prog. Org. Coat. 129 (2019) 147-158.

[32] E. Javadi, M. Ghaffari, G. Bahlakeh, P. Taheri, Photocatalytic, corrosion protection and adhesion properties of acrylic nanocomposite coating containing silane treated 
nano zinc oxide: a combined experimental and simulation study, Prog. Org. Coat. 135 (2019) 496-509.

[33] N. Sheng, Y. Lei, A. Hyonoo, M. Ueda, T. Ohtsuka, Improvement of polypyrrole films for corrosion protection of zinc-coated AZ91D alloy, Prog. Org. Coat. 77 (2014) 1724-1734.

[34] G. Kalavathy, G. Baskar, Synergism of clay with zinc oxide as nanocatalyst for production of biodiesel from marine Ulva lactuca, Bioresour. Technol. 281 (2019) 234-238.

[35] K. Jlassi, M.H. Sliem, K. Fid, I. Krupa, M.M. Chehimi, A.M. Abdullah, Novel enzyme-free multifunctional bentonite/polypyrrole/silver nanocomposite sensor for hydrogen peroxide detection over a wide pH range, Sensors 19 (2019) 4442.

[36] J. Martins, M. Bazzaoui, T. Reis, E. Bazzaoui, L. Martins, Electrosynthesis of homogeneous and adherent polypyrrole coatings on iron and steel electrodes by using a new electrochemical procedure, Synth. Met. 129 (2002) 221-228.

[37] K. Jlassi, A. Mekki, M. Benna-Zayani, A. Singh, D.K. Aswal, M.M. Chehimi, Exfoliated clay/polyaniline nanocomposites through tandem diazonium cation exchange reactions and in situ oxidative polymerization of aniline, RSC Adv. 4 (2014) 65213-65222.

[38] M. Hosseini, L. Fotouhi, A. Ehsani, M. Naseri, Enhancement of corrosion resistance of polypyrrole using metal oxide nanoparticles: potentiodynamic and electrochemical impedance spectroscopy study, J. Colloid Interface Sci. 505 (2017) 213-219.

[39] N.H. Othman, W.Z.N. Yahya, M. Che Ismail, M. Mustapha, Z.K. Koi, Highly dispersed graphene oxide-zinc oxide nanohybrids in epoxy coating with improved water barrier properties and corrosion resistance, J. Coat. Technol. Res. 17 (2020) 101-114.

[40] A. Khan, M.H. Sliem, A. Arif, M.A. Salih, R.A. Shakoor, M.F. Montemor, R. Kahraman, S. Mansour, A.M. Abdullah, A. Hasan, Designing and performance evaluation of polyelectrolyte multilayered composite smart coatings, Prog. Org. Coat. 137 (2019), 105319.

[41] M.H. Sliem, M. Afifi, A. Bahgat Radwan, E.M. Fayyad, M.F. Shibl, F.E.-T. Heakal, A. M. Abdullah, AEO7 surfactant as an eco-friendly corrosion inhibitor for carbon steel in HCl solution, Sci. Rep. 9 (2019) 2319.

[42] K. Shahzad, M.H. Sliem, R.A. Shakoor, A.B. Radwan, R. Kahraman, M.A. Umer, U. Manzoor, A.M. Abdullah, Electrochemical and thermodynamic study on the corrosion performance of API X120 steel in 3.5\% NaCl solution, Sci. Rep. 10 (2020) 4314.

[43] M. Rostami, S. Rasouli, B. Ramezanzadeh, A. Askari, Electrochemical investigation of the properties of $\mathrm{Co}$ doped $\mathrm{ZnO}$ nanoparticle as a corrosion inhibitive pigment for modifying corrosion resistance of the epoxy coating, Corros. Sci. 88 (2014) 387-399.

[44] K. Jlassi, A.B. Radwan, K.K. Sadasivuni, M. Mrlik, A.M. Abdullah, M.M. Chehimi, I. Krupa, Anticorrosive and oil sensitive coatings based on epoxy/polyaniline/ magnetite-clay composites through diazonium interfacial chemistry, Sci. Rep. 8 (2018) 13369.

[45] Y. Cubides, H. Castaneda, Corrosion protection mechanisms of carbon nanotube and zinc-rich epoxy primers on carbon steel in simulated concrete pore solutions in the presence of chloride ions, Corros. Sci. 109 (2016) 145-161.

[46] R. Alam, M. Mobin, J. Aslam, Investigation of anti-corrosive properties of poly (aniline-co-2-pyridylamine-co-2,3-xylidine) and its nanocomposite poly(aniline-co2-pyridylamine-co-2,3-xylidine)/ZnO on mild steel in 0.1M HCl, Appl. Surf. Sci. 368 (2016) 360-367.

[47] T. Ge, W. Zhao, X. Wu, Y. Wu, L. Shen, X. Ci, Y. He, Design alternate epoxy-reduced graphene oxide/epoxy-zinc multilayer coatings for achieving long-term corrosion resistance for Cu, Mater. Des. 186 (2020), 108299. 